\title{
Chronic alpha-irradiation of the nervous system from thorium dioxide
}

\author{
E H Jellinek DM FRCP
}

J R Soc Med 2004;97:345-349

The discoveries by A $\mathrm{H}$ Becquerel of the radioactivity of uranium ore in 1895 and of X-rays by W Röntgen in 1896 were soon followed by the appreciation of biological effects, initially on the skin of the physicists themselves. Pierre Curie reported animal experiments in $1904,{ }^{1}$ shortly before his death in a road accident; his wife, Marie, was to succumb to radiation damage 30 years later. The hazards of the deeply penetrating X-rays (gamma radiation) led to appropriate measures by physicists, physicians and governments, ${ }^{2,3}$ but the very short-range (Figure 1) and slower effects of alpha particles from thorium dioxide, an excellent radiological contrast medium introduced in $1928 / 9,{ }^{4}$ were treated more cavalierly until half-way into the twentieth century, long after the tragedy from alpha radiation of the luminous watch-dial painters in New York in $1925 .{ }^{5}$ Thorium dioxide (Thorotrast) was still marketed in 1967 for radiodiagnosis. ${ }^{6}$

The long delayed and insiduously fatal effects of alpha radiation, with postmortem findings, are described here in two men who had Thorotrast ventriculography in 1937 and in 1938, 44 and 30 years before they died. Case 2 was reported intra vitam in $1952 .{ }^{7}$

\section{CASE HISTORIES}

\section{Case 1}

The patient was admitted, aged 19, in 1937 to the Edinburgh Royal Infirmary with a nine-week history of tonsillitis and earache, and increasing headache. He was very ill, temperature $40^{\circ} \mathrm{C}$, and complained of double vision and episodic loss of sight. There was papilloedema, and Mr (later Professor) Norman Dott suspected a spaceoccupying lesion deep in the midline of the brain which required ventriculography. At first Mr G Alexander injected oxygen via two burr-holes into the lateral ventricles. This caused 'frenzy'. The patient was then anaesthetized: $3 \mathrm{~mL}$ of Thorotrast was injected into each lateral ventricle and $\mathrm{X}$ rays were taken. Evacuation of the contrast was incomplete: 'not very well cleaned out'. Mr Dott then turned a right parietal flap and explored the pineal region - a procedure he had to abandon, leaving ventricular drains.

7 Oxgangs Road, Edinburgh EH10 7BG, Scotland, UK

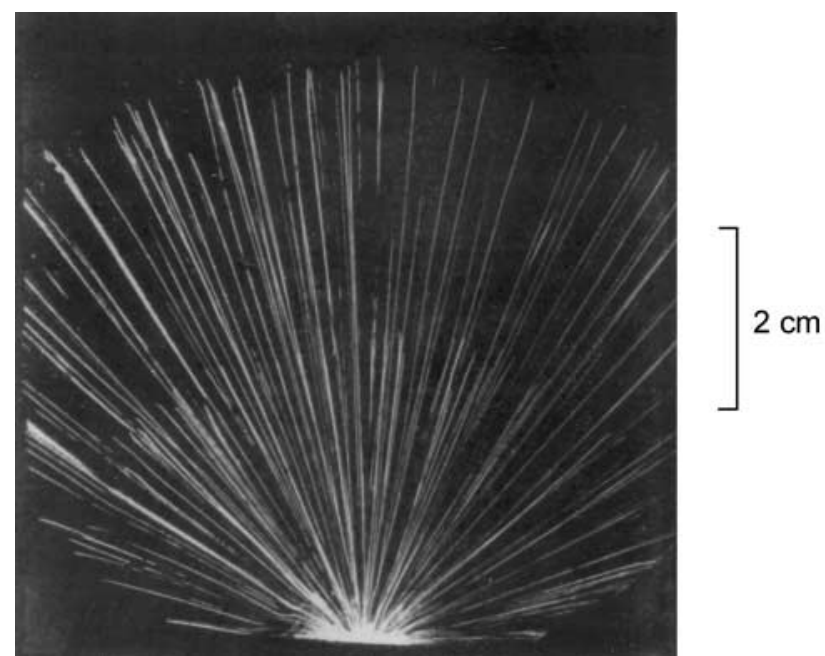

Figure 1 Alpha particle tracts in air from thorium. Photograph by $\checkmark$ Chadwick (Reproduced from Lord Rutherford's New Alchemy, University Press, Cambridge, 1937)

$2 \frac{1}{2}$ months later the young man was better but the bone flap was elevated by $15 \mathrm{~mm}$. The craniotomy site was reexplored and 'a membrane removed'; Staphylococcus aureus was cultured. One month on, a bone sequestrum came away; the patient then made a seemingly complete recovery and was working as a joiner by May 1939 .

After the outbreak of war he joined an infantry regiment, with which he fought as a non-commissioned officer in the defence of India and the reconquest of Burma from the Japanese. In 1946, 9 years after the ventriculogram, when he worked again as a joiner, he had a facial palsy deemed initially 'only of academic interest'; but it did not remit, and deafness on the same side was added in 1950. By 1953 the patient also had cauda equina symptoms and signs - sacral sensory loss, unsteadiness and poor bladder emptying. In 1954 Norman Dott wrote '... 16 years ago probably post-otitic sinus thrombosis'. The lower spinal theca was explored in the futile hope of removing Thorotrast remains from a fibrotic and cystic subarachnoid space. For good measure Professor Dott also performed tarsorrhaphies and unilateral hypoglossal-facial anastomosis to alleviate the by now bilateral and severe facial palsy and eye exposure.

The patient managed to work as a joiner till 1958, and then as a shop assistant till 1966. By 1970 he needed two 


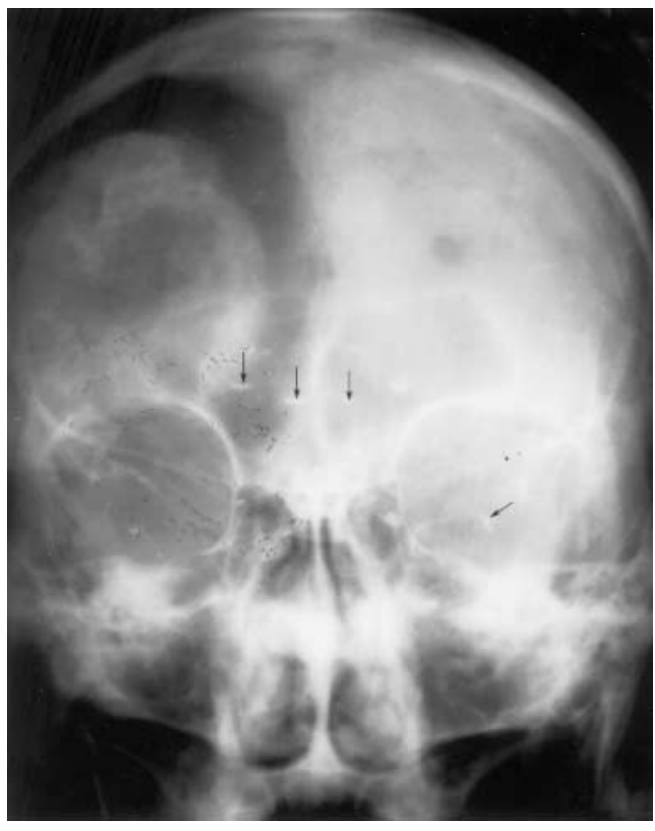

Figure 2 Case 1, skull X-ray in 1973. Porotic skull flap of 1937 right parietal craniotomy. Traces of Thorotrast in floor of ventricles and around base of brain (arrowed)

elbow crutches but was able to drive for another 3 years. By 1972 he was totally deaf, and had a rectal prolapse. When he came under my care in 1973 (Figures 2 and 3) he had defects of all cranial nerves on both sides and a flaccid paraparesis. He later required a bladder catheter and a colostomy. He suffered a fractured femur and was in and out of hospitals, latterly in a spinal injury unit, until his death in 1981, aged 63, 44 years after the ventriculogram with Thorotrast.

\section{Postmortem findings (Dr A Gordon, Western General Hospital, Edinburgh)}

'Emaciated body with operation scars ... atheroma... aneurysm of abdominal aorta... Difficult removal of brain and cord ... fibrotic adhesions ... affecting optic nerves and chiasm [Figures 4 and 5]... dural tube grossly thickened... at lumbar operation site $8 \mathrm{~cm}$ cyst... initial impression that the cauda equina had disappeared... After

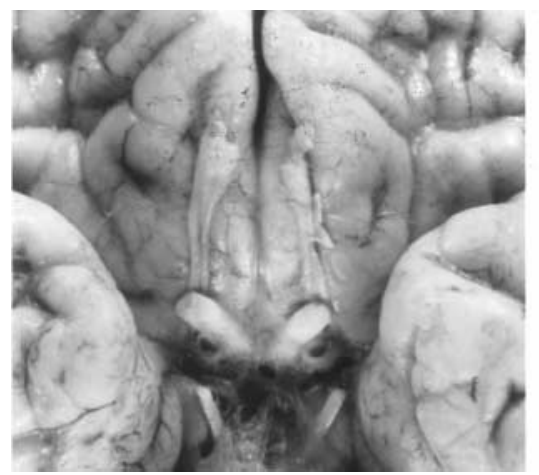

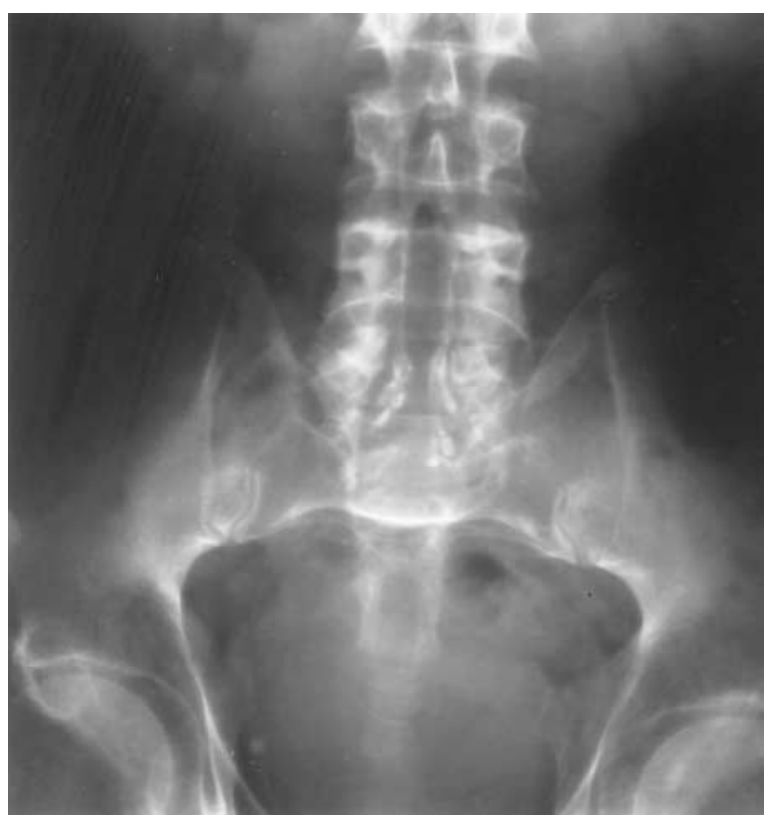

Figure 3 Case 1 in 1973, lumbar spine X-ray. Laminectomy bone defects; Thorotrast outlining lumbosacral theca and some nerve roots

fixation brain looked relatively normal with only slight dilatation of ventricles... A little Thorotrast in floor of frontal horns ... Spinal cord adherent to posterior dural tube, slight shrinkage thoracic to sacral segments... atrophy of thoracic roots down to sacral roots, cauda equina embedded in fibrous dural tube... On microscopy the cerebral cortex was relatively unaffected, with mild marginal layer gliosis. In the leptomeninges there were collections of refractile yellowish material (Thorotrast) related to (normal) blood vessels. Most of the choroid plexus contained thorium dioxide to which there was some fibrous reaction... There was loss of ependyma in the floor of lateral ventricles where there was a mass of Thorotrast with mild astrocytic proliferation in the underlying white matter. Aqueduct and 4th ventricle floor... long-standing ependymitis. Mid-brain, pons and medulla essentially normal despite thorium in overlying meninges and adjacent oculomotor nerves. Cerebellum... irregular loss of

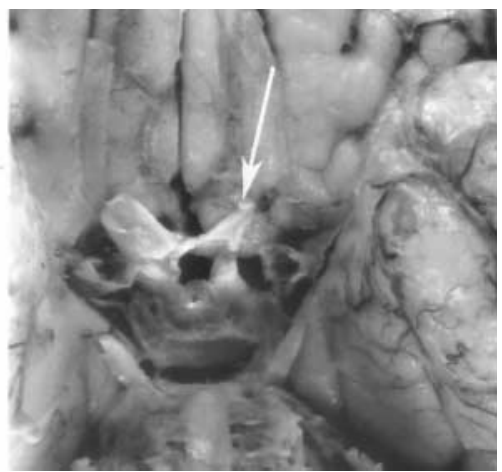


Purkinje cells and gliosis in the molecular layer, with considerable amount of thorium in overlying meninges, unrelated to hyalinisation in walls of blood vessels... The pituitary was intact despite a massive slab of hyaline collagen virtually devoid of fibroblasts but densely infiltrated with seams of thorium, sometimes within histiocytes. Attached are the gliotic remnants of the optic nerves. There was irregular and sometimes gross degeneration of spinal roots at all levels, particularly dorsal, accompanied by degeneration of the fasciculus gracilis. Roots medial to dorsal root ganglia showed often gross fibrosis and loss of myelinated fibre bundles but no inflammatory reaction. The subarachnoid space was obliterated by masses of connective tissue with seams of thorium, often within macrophages, most strikingly in root pockets, cauda equina a fused mass infiltrated with thorium containing macrophages, degeneration of both myelin sheaths and axis cylinders. Autoradiographs of sections of cerebellum and lumbar dural tube showed short dotted black lines radiating from the refractile material interpreted as alpha particle tracts.' [Figure 6]

\section{Case 2}

This patient was 22 at the time of his Thorotrast ventriculogram in 1938 and his early history was recorded by R Hughes in $1953 .{ }^{7}$ He had initially presented to an ophthalmologist in 1938 with a three-month history of headache, and was found to have mild bilateral papilloedema but apparently no other abnormality. After lumbar air-encephalography had shown displacement of both frontal horns to the right, a ventriculogram with $5 \mathrm{~mL}$ Thorotrast confirmed the ventricular displacement. '... Although a diagnosis of intracranial tumour was made...no surgical procedure was attempted.' $\mathrm{He}$ returned to work as a tailor's presser about a year later, then joined the Army, served in South-East Asia, rose to warrant officer rank, and was discharged in 1948 in medical category A1. In August 1951, 13 years after the Thorotrast ventriculogram, he attended the Liverpool neurological clinic with a four-month history of lower abdominal distension, urinary frequency and incontinence, and slight numbness of one buttock. He was found to have overflow incontinence, a patulous anus, and signs of a cauda equina lesion. X-rays showed Thorotrast in the skull and in the lower spinal theca; air encephalography demonstrated 'a moderate degree of symmetrical hydrocephalus', with Thorotrast lining the dependent parts (Figure 7).

His later history is summarized in the pathologist's postmortem report. In 1958 he had become deaf. At the final hospital admission in January 1968: 'Difficulty walking 3 years. Incontinence of urine. Sensory loss in saddle area S 2, 3, 4, 5. Motor power normal. Reflexes reduced in

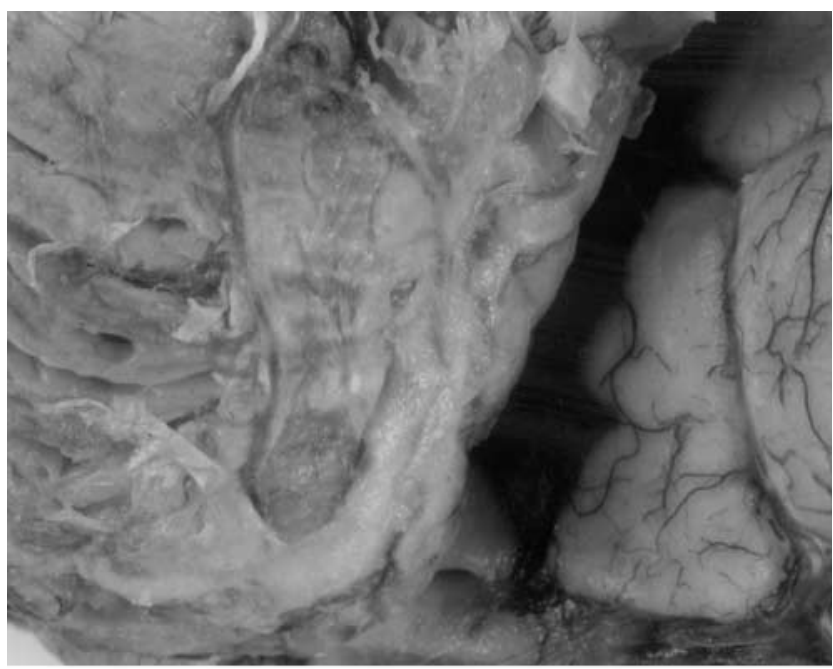

Figure 5 Case 1: Thorotrast overlying cerebellar and cerebral cortex, 'almost like a purulent exudate' as reported in case 2

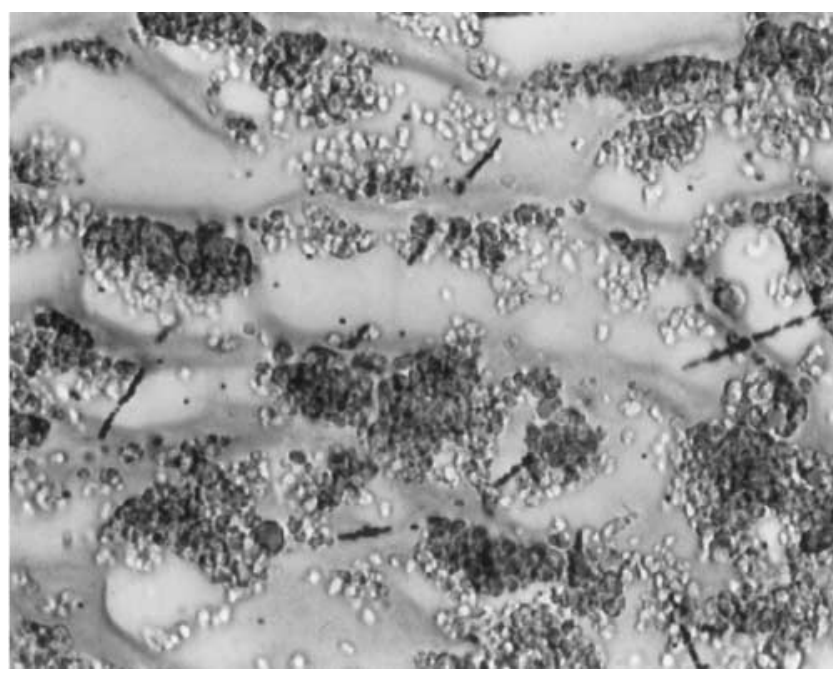

Figure 6 Case 1: microscopy of Thorotrast deposit $(\times 100)$.

Autoradiography shows short straight lines of path of alpha particles

legs - plantars flexor —?diabetes insipidus - polyuria, polydipsia. Slowly deteriorated with chest infection and electrolyte disturbance.' He died aged 53, 30 years after the Thorotrast ventriculogram, about 17 years after onset of cauda equina symptoms, and about 10 years after he complained of deafness.

\section{Postmortem findings (Dr P Buxton, Walton Hospital, Liverpool)}

'Meninges: dura thicker and more opaque than normal, particularly left temporal ... yellowish left fronto-temporal subdural cystic cavity $5 \mathrm{~cm}$ diameter, maximum $2 \mathrm{~cm}$ deep, with clear straw coloured fluid, at anterior end of middle fossa compressing temporal pole and sylvian fissure, adjacent marked secondary atrophy... Whitish plaques on the diaphragma sellae and on the adherent meninges... Posterior fossa meningeal adhesions superior surface of 


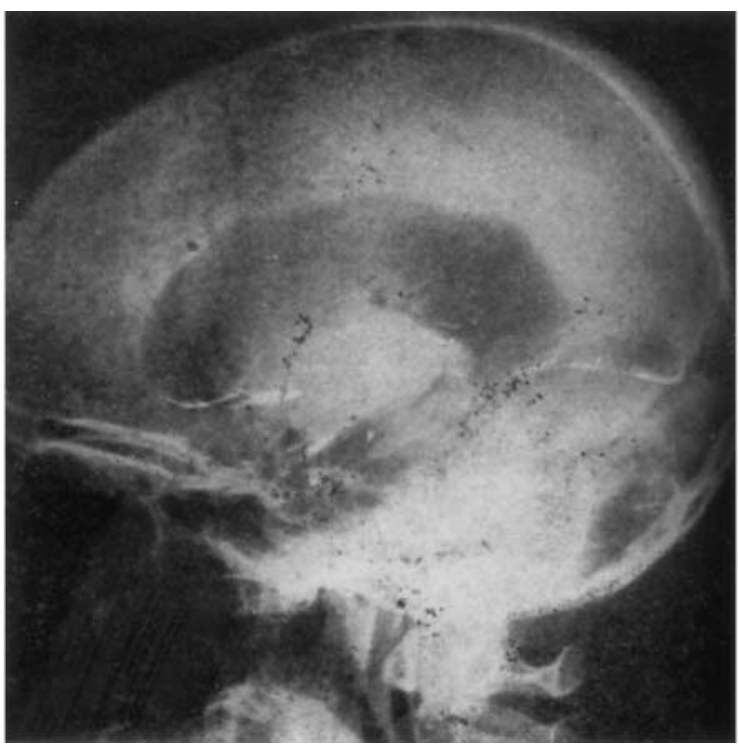

Figure 7 Case 2 in 1951, 13 years after ventriculography: air encephalogram. Moderate symmetrical dilatation of ventricles with Thorotrast outlining dependent parts (Ref. 7)

cerebellum ... appearing almost like a purulent exudate. Meningeal thickening extended to cisterna magna and 4th ventricle foramina, marked in cerebello-pontine angle... Irregular thickening of dura and arachnoid lower cord, adhesions and congestion of cauda equina roots ... Pituitary small, thickened diaphragma sellae. Provisional diagnosis: post-thorium meningeal granulomatosis.'

The late Dr Buxton's histological report of 1968 has been lost. In 2004 Dr J Broome found a few histological slides of brain, cord and meninges with extensive deposition of darkly pigmented granular foreign body material, mainly in the meninges, extending in some areas into the cortex, leading to neuronal loss and gliosis, but no slides of the pituitary.

\section{DISCUSSION}

The primary cerebral disorder in the first case seemed lifethreatening, with raised intracranial pressure, and was investigated by ventriculography in 1937, when neuroradiology was in its infancy, ${ }^{8}$ but this did not spare the patient futile surgical exploration for a deep midline tumour. The presenting illness of the second case is harder to assess but he too made a spontaneous recovery from months of raised intracranial pressure. The extracerebral cyst found at postmortem may be relevant. In both men the indications for ventriculography were valid although subsequent management is more debatable.

Air and oxygen ventriculography was introduced by Dandy in 1918/19, ${ }^{8}$ and was followed by trials of heavy contrast media. Sicard introduced Lipiodol in 1921, and used as a general radiological contrast medium in 1928/9 in Berlin, ${ }^{4}$ and then in the brain by Egas Moniz in Lisbon. ${ }^{9}, 10$

Thorotrast gave pictures with excellent contrast, and was well tolerated in the short run. It was injected into the cerebral ventricles and into the lumbar subarachnoid space, and it was used even more by intravascular injection for cerebral arteriography. ${ }^{11}$

The radioactivity of thorium was of course known to the originators in 1928 but was discounted because it was feeble and decay was so slow-half-life millions of years. Its radioactivity consisted almost entirely of very short range alpha particles, with negligible penetrating gamma radiation.

The biological effects of radiation ${ }^{2,3,12}$ had been appreciated since the first years after the discoveries of radioactivity and of X-rays in 1895 and 1896, and were attributed to gamma radiation. The dramatic dangers also from alpha radiation were published from New York in $1925^{5}$ but were ignored by the originators of the medical use of Thorotrast in Berlin in 1928 and 1929,13 and by Moniz in Lisbon in the 1930s. ${ }^{9}, 10$

As well as being an excellent contrast medium, Thorotrast was devoid of the immediate bad, and sometimes lethal, side-effects of the oily Lipiodol and of aqueous iodide solutions when injected into blood vessels and body cavities. ${ }^{9}, 10$ Thorotrast became increasingly popular all over the world in the 1930s, despite some early warnings of bad long-term effects, initially from animal experiments. ${ }^{14,15} \mathrm{In}$ Norman Dott's neurosurgical unit in Edinburgh it was used for 141 arteriograms between 1928 and 1955, and in 27 patients for ventriculography and myelography from 1931 to 1941. ${ }^{16}$ Egas Moniz, the pioneer of arteriography, referred in his monographs of 1931 and 1934 to his own satisfactory use of Thorotrast in Lisbon (without giving figures), and to Dott's use of it in Edinburgh, but specified that air and oxygen were preferable for ventriculography. ${ }^{9,10}$

By 1938 leading articles in The Lancet ${ }^{14}$ and the British Medical Journa $1^{15}$ marshalled the evidence against Thorotrast, and declared it unsafe. Its use waned, but it was still marketed in $1968^{6}$ for injection into brain abscess cavities prior to excision.

The intravascular use of Thorotrast worldwide in thousands of patients as a cause of delayed neoplasia, etc., including even more delayed potential genetic effects, has been the subject of two symposia - in New York in 1967, ${ }^{13}$ with 37 contributors, and in Japan in 1999, ${ }^{17}$ with 33 contributors. There have also been a few reports of 'Thorotrastomas' from accidental extravasation, causing late vascular occlusion or distorting fibrosis, chiefly in the neck after arteriography. ${ }^{18}$

The delayed afflictions of the few long survivors of subarachnoid Thorotrast, for ventriculography and myelography, have also led to some single case reports. ${ }^{19-23}$ The only bigger series dealt with the 27 Edinburgh patients who 
had received subarachnoid Thorotrast, 17 of whom had died from their primary condition. Out of the 10 who had survived more than 5 years 7 developed cauda equina symptoms, of whom 6 had died of renal failure; the one survivor in the 1967 paper $^{16}$ is case 1 in this article: he did not succumb till 1981.

Thorium dioxide is not excreted, and only a minute fraction of its radioactivity is exhaled. While intravascular Thorotrast becomes fixed in the reticuloendothelial system-i.e. liver and spleen in the main, where it can trigger later neoplasia - the subarachnoid Thorotrast gravitated down to the dependent recesses of the subarachnoid space, around the base of the brain and into the spinal root pockets and the lumbosacral sac, where it is 'fixed'.

The alpha radiation of thorium consists of positively charged helium nuclei. These have a range of $4.6-8.6 \mathrm{~cm}$ in gas (Figure 1) but a range of only a few millimetres in animal tissues (Figure 6). The alpha particles cause ionization and cell damage within this range in the craniospinal compartments. The affected tissues are chiefly the meninges and cranial nerves at the base of the brain, and meninges and spinal roots below. The brain and cord are not directly affected, but the cord eventually suffers secondary posterior column degeneration from the radiation damage to the sensory roots and ganglia in the spine. Very chronic alpha radiation thus damages those tissues (meninges, cranial nerves and spinal roots and nerves) which are relatively insensitive to acute gamma radiation, as used in radiotherapy, but not the brain and cord, which are conversely vulnerable to gamma radiation, which may cause encephalopathy ${ }^{24}$ and myelopathy. ${ }^{25}$

Another theoretical effect of chronic alpha radiation is a disturbance of cerebrospinal fluid circulation. This did not happen in case 1; case 2 exhibited some hydrocephalus (dilated ventricles) in the 1951 air encephalogram, but the left subdural cyst probably antedated the Thorotrast ventriculogram in 1938 when the ventricles were reported displaced to the right side.

Thorotrast was found in both cases at postmortem around the diaphragma sellae. It had destroyed the chiasm and optic nerves in case 1 but left his pituitary intact. However, the second patient suffered terminal diabetes insipidus; at necropsy the pituitary seemed small, but histology unfortunately went astray. Thus the alpha radiation led to an indolent but lethal progressive fibrosis and granulomatosis adjacent to the Thorotrast residues but hardly affected brain and cord in these two men.

Acknowledgments I am indebted to Mrs Frances Scott, of Hawick, for permission to write about her late husband (case 1), and to Dr Alex Gordon for his meticulous postmortem studies and helpful discussions; in Liverpool to the late Dr Robert Hughes and the late Dr Peter Buxton for information about case 2. Dr John Broome kindly tried to trace the missing brain histology of 1968 .

\section{REFERENCES}

1 Bouchard C, Curie P, Balthazard V. Action physiologique de Radium. C R Acad Sci (Paris) 1904;138:1384-7

2 Oliver K. 75 years of radiation protection. Br J Radiol 1973;46:954-60

3 Burrows EH. Pioneers and Early Years - A History of British Radiology. Alderney CI: Colophon, 1986

4 Blühmbaum T, Frik K, Kalkbrenner H. Neue Anwendungsart der Kolloide in der Röntgendiagnostik. Fortschr Geb Röntgenstrahlen 1928;37:18-29

5 Martland HS, Conlon P, Knef J. Some unrecognised dangers in the use and handling of radioactive substances. JAMA 1925;85:1769-76

6 Granger GA. Use of Thorotrast. BMJ 1967;ii:112

7 Hughes R. Chronic changes in the central nervous system following Thorotrast ventriculography. Proc R Soc Med 1953;46:191-5

8 Bull JWD. The history of neuroradiology. In: Rose FC, Bynum WF, eds. Historical Aspects of the Neurosciences. New York: Raven, 1982

9 Moniz E. Diagnostic des Tumeurs Cérébrales et Epreuve de l'encéphalographie Artérielle. Paris: Masson, 1931

10 Moniz E. L'angiographie Cérébrale. Paris: Masson, 1934

11 Twining EW, Rowbotham GF. Ventriculography by opaque injection. Lancet $1935 ; \mathbf{i i}: 122-5$

12 Alexander P. Atomic Radiation and Life. Harmondsworth: Penguin, 1965

13 Swarm RL, ed. Late effects of thorium dioxide. Ann $N$ Y Acad Sci 1967; 145:523-858

14 Anon. The dangers of Thorotrast. Lancet 1938;1:36

15 Anon. Is Thorotrast safe? BMJ 1938;1:903

16 Boyd JT, Langlands AO, Maccabe JJ. Long-term hazards of Thorotrast. BMJ 1968;ii:517-21

17 Machinami R, et al. Workshop on health effect of Thorotrast ... other alpha emitters. Radiat Res 1999;152(suppl):1-171

18 Schlemmer HP, Liebermann D, Naser V, van Kaick G. Locoregional late effects of paravascular Thorotrast. J Neuroradiol 2000;27: 253-63

19 Maltby G. Progressive post-Thorotrast myelopathy. $N$ Engl J Med 1964;270:490-6

20 Dale A, Love J. Thorium dioxide myelopathy. JAMA 1967;199:606-9

21 Meyer M, Powell H, et al. Thorotrast induced arachnoiditis associated with meningioma and Schwannoma. Hum Pathol 1978;9: $366-70$

22 Freilich D. Cauda equina lesion due to Thorotrast. Aust NZ J Med 1983;13:283-4

23 Pandya PM, Keogh AJ. Arachnoiditis following intracranial Thorotrast. Clin Radiol 1992;45:141-3

24 Holdorf J. Radiation damage to the brain. In: Vinken PJ, Bruyn G, eds. Handbook of Clinical Neurology, Vol. 23. Amsterdam: North Holland, 1975: 639-63

25 Vecht CJ, van der Kogel AJ. Radiation myelopathy. In: Vinken PJ, Bruyn G, Frankel HL, eds. Handbook of Clinical Neurology, Vol. 61. Amsterdam: North Holland, 1992:199-213 